\title{
Editorial
}

\section{La globalización anda en pena}

La globalización sufre de un mal interno: nunca ba estado el mundo tan unido y, a la vez, tan dividido por la misma globalización. Franz Hinkelammert dijo: "El proceso de globalización pasa desde hace más de dos décadas por encima de América Latina, asi como pasa por encima del mundo entero, como un buracán". La globalización presenta los rasgos de un imperio que atraviesa todas las fronteras, debilita los poderes politicos y económicos de los Estados, irrespeta los valores tradicionales en que se fundamenta la existencia de cada nación y pretende imponer una homogeneización cultural a la que se ajusten todas las actividades. En su estado actual, la globalización será recordada como la era de las grandes desigualdades. Al ser un imperio político, económico, tecnológico, cultural y, por añadidura, militar, la globalización está generando crecientes movimientos centrifugos.

Hace cuatro años Arthur Scblesinger, asesor del ex presidente John F. Kennedy, afirmaba que la globalización estaba generando dos vias de movimientos centrifugos: los que buscan el refugio de su identidad en los enclaves religiosos, étnicos o tribales, y quienes, 
más allá de la resistencia pasiva, adoptan reacciones de rechazo y enfrentamiento. "La integración y la desintegración se alimentan mutuamente". A partir del 11 de septiembre se puede decir que algunos grupos convergen en una declarada confrontación. En el foro económico mundial de Davos-Nueva York se babló de la 'globalización de la ira', acelerada por el rápido crecimiento de las desigualdades.

No podemos negar los grandes aportes de la moderna revolución tecnológica, uno de los ejes de la globalización, porque la microelectrónica, la informática, la biotecnologia, los nuevos productos y los nuevos procesos de producción mejoran la calidad empresarial, los servicios públicos y privados, sirven a combatir pandemias y pueden propiciar un tiempo mayor al aprendizaje y al ocio cultural. Pero, como se ha repetido tantas veces, las revoluciones tecnológicas son "un proceso de creación destructiva" ('destrucción creativa', de J. Schumpeter), al mismo tiempo que la actual revolución tecnológica amenaza con destruir más puestos de trabajo que los que crea, generando un crecimiento con desempleo. Al estar el conocimiento tecnológico más concentrado que la riqueza y el capital, o formar los tres una misma simbiosis, la globalización ha gestado un proceso de exclusión de otros modos tradicionales $u$ obsoletos de producción y un proceso de dominación a través de los derechos de propiedad intelectual. Por ello se ha dicho que 'la globalización hace dificil la globalización'.

No es de extrañar que en los uiltimos cuatro o cinco años, alli donde se reunen los grandes actores de la globalización (G-7, FMI, $B M, O M C$, Davos...) se haya ido congregando un creciente $y$ beterogéneo número de manifestantes pacificos que, en sus propuestas alternativas, nos vienen diciendo que es necesario 'gobernar la globalización'. A este respecto bay que afirmar que los manifestantes violentos (llamados "flores venenosas") prestan el peor de los servicios porque la violencia es la negación de la propuesta alternativa.

Como normalmente los actores de la globalización se reúnen en el hemisferio Norte, alli también se congregan los manifestantes en 
representación del Norte y del Sur, porque la globalización ba gestado un tercer mundo al interior del primer mundo y un primer mundo dentro del tercero. Muchos gobiernos del hemisferio Sur no quieren entender que los manifestantes y las manifestaciones son un derivado congénito de la globalización y un esfuerzo positivo por crear una mundialización donde quepa toda la bumanidad. Fieles creyentes de una teoría del libre mercado, que convierte a sus pueblos en excluidos, estos gobiernos son la quinta columna del primer mundo en el tercer mundo.

La globalización es engañosa y los actores de la globalización son artistas del engaño: para defender su teoria, irrespetan las normas de su teoría. Esto es claro en el ámbito del comercio internacional. En la cumbre de la Organización Mundial del Comercio (OMC), tenida en Seattle, diciembre 1999, más de 40.000 manifestantes se congregaron como 'la voz de los sin voz' $y$, por primera vez en la historia, los delegados de los paises en desarrollo se negaron a firmar un documento final, cuyos borradores desconocian y sobre el cual no habian sido consultados. Sabemos que el fantasma de Seattle ha sobrevolado todas las cumbres mundiales hasta la ajetreada y turbia cumbre de la OMC en Doba, Qatar, celebrada el mes de noviembre de 2001.

Con toda razón, Joseph Stiglitz dijo que el libre comercio en poco o en nada ba beneficiado a los paises en desarrollo y que la teoria del libre comercio era "un fraude intelectual". Aunque esta afirmación le costó su puesto de jefe de economistas del Banco Mundial, J. Stiglitz — a despecho de sus detractores- ba sido galardonado con el Premio Nobel de Economía 2001 por su "Teoría de las Asimetrias". Dirigiéndose a los representantes del G7/8, reunidos en Génova, en julio de 2001, J. Stiglitz dijo: "El sistema del comercio global está en problemas. Se predica el libre comercio como el evangelio en todas partes, pero parece que los países ricos no bacen caso de su mensaje; sus mercados permanecen cerrados a muchos de los productos de los paises en desarrollo, subsidian sus agriculturas en forma masiva, lo que bace imposible que los paises en desarrollo puedan competir. El mensaje del G-7 parece ser: ba- 
gan lo que decimos, no lo que bacemos". Este testimonio de J. Stiglitz resume los reclamos de Seattle, Bangkok, cumbre del Milenio $y$ Qatar, porque al mismo tiempo que los paises ricos prometen aliviar escuetamente la deuda externa del tercer mundo, la recrean $y$ multiplican con las relaciones asimétricas del comercio internacional. La globalización no tiene corazón.

También los actores de la globalización se ven sometidos a los arrebatos de la globalización gestados en las entrañas del mercado de capitales financieros especulativos que, a su tiempo, sacuden las bolsas de valores. Luego de la crisis financiera mundial de 19971998 y ante el desconcierto del G-7 reunido en Washington, M. Elliot concluia: "A la pregunta: ¿quién está a cargo de la economía global?, la respuesta es: Nadie. Un mundo sin controles -sin reglas- es un mundo sin seguridad". Estados Unidos, en primer lugar, ha sido arrollado por su propia globalización. En la reunión de Davos 2000 soplaban aires nuevos: la nueva economia, asentada en el Internet y las telecomunicaciones, aseguraria un crecimiento ilimitado junto con una racionalidad bursátil; las futuras recesiones tendrán un efecto mucho menor y menos grave sobre la actividad económica, los beneficios empresariales y la cotización de las acciones. La economia mundial crecerá un $4 \%$. Seis meses después la economia norteamericana iniciaba un proceso de ralentización y, al cerrar el año Alan Greespan dijo: "nuestra tasa de crecimiento probablemente es cercana a cero".

La explicación bay que buscarla en el espiritu, propensión o instinto de especulación que, al fin y al cabo, es el arte de vivir del trabajo ajeno. En la reunión de Davos 2000, el secretario del Tesoro, Larry Summers, y Stanley Fischer, del FMI, dieron su voz de alerta, "mostrando su preocupación por el bajo aborro y elevado endeudamiento de los hogares norteamericanos y que en caso de ralentización económica colocaría en dificultades a muchas familias". Dijeron "estar inquietos por la desbocada marcha de la economia norteamericana, que podría verse abocada a una caída drástica en el caso de que los actuales ritmos de crecimiento no pudieran ser controlados". 
Arrastrados por la exuberancia de la bolsa de valores, muchos hogares norteamericanos invirtieron masivamente sus aborros, $e$ incluso nuevos créditos, en títulos valores de telecomunicaciones. Dado el comportamiento atípico de la oferta y demanda en bolsa de valores, inicialmente las cotizaciones de estos títulos subian más deprisa que los costos de inversión, atrayendo crecientes inversiones, hasta el momento en que el elevado precio de las acciones reduce las expectativas de los dividendos reales, y el mercado opta por la venta acumulada de estos títulos valores. Asi lo explica el bistoriador Lester Thurow: "Aquellos que invirtieron en infraestructura de telecomunicaciones se encontraron con que el valor de sus acciones subia más que los costos de las inversiones. Hoy dia, después de la caida, el mercado de valores está haciendo exactamente lo contrario. Aquellos que contrajeron grandes deudas para financiar la infraestructura de telecomunicaciones están siendo penalizados por esas enormes deudas".

Esto significa que la especulación alocada de tantos hogares norteamericanos ha reducido el indice de confianza de los consumidores estadounidenses, prolongando la ralentización (irrecesión?) de su economia, que a su vez ha afectado la ralentización de nuestras economias dependientes. Lester Thurow dirá que la abierta recesión de Japón se gesto, en buena parte, por la gran especulación inmobiliaria, y que Europa puede ser víctima de la especulación en telecomunicaciones, similar a la norteamericana. En marzo 2002, Alan Greespan anuncia que hay signos de una moderada recuperación de la economía de Estados Unidos; pero en enero 2002, luego del escándalo Enron, se declara en quiebra la firma Global Crossing, primera estrella en el ramo de la fibra óptica y telecomunicaciones, arrastrando en su caida a otras empresas. Los fraudes especulativos y fiscales siguen a la orden del dia y la globalización anda en pena.

La globalización está sometida a serios ciclos económicos en el primer mundo y no ofrece esperanzas al tercero. Si en el foro de Davos 2000 soplaban vientos de euforia, exuberancia y racionalidad, en el foro económico de Davos 2001 sus dos puntos de agenda anunciaban el fracaso: "recuperar el crecimiento y corregir las des-

415

La globolizoción ando en peno 
igualdades". Ni crecimiento económico, ni desarrollo bumano. En el año 2001 la globalización presenta una novedad. En las mismas fechas en que los 'conformes' con la globalización se reúnen en Davos, los 'inconformes', grupo heterogéneo y numeroso, se congregan en Porto Alegre, con el ánimo de sustituir la protesta por la propuesta: "otro mundo es posible". Si en Davos el análisis es más economicista y financiero, en Porto Alegre es la sociedad civil la que lleva a cabo un análisis más social y propositivo. Esto entraña un cambio cuantitativo y cualitativo. Si en Porto Alegre 2001 se reúnen 20.000 delegados, en Porto Alegre 2002 se congregan más de 50.000 participantes de 150 paises diferentes. Abora hay dos lecturas de la globalización y las dos lecturas, desde sus perspectivas económica y social, dicen que la globalización anda en pena: 'economia frágil, economia de la inseguridad, globalización de la ira'...

Los Estados Unidos representan un poco menos del $5 \%$ de la población mundial, consumen el $27 \%$ del petróleo mundial; generan el $30 \%$ del PIB mundial y totalizan el $40 \%$ del gasto armamentístico mundial. Esto significa que los actos terroristas del 11 septiembre marcan una quiebra en el eje de la globalización. Los corazones del mundo entero deben acomodar sus pulsaciones al ritmo de los latidos del corazón norteamericano. 'Quien no esté en contra de los terroristas, está en nuestra contra'. La globalización se paraliza $y$ se concentra en los Estados Unidos y sus aliados: terrorismo es el 11 septiembre y, luego de los dias de las condolencias, "ba llegado el momento de la acción".

El documento final de Porto Alegre inicia con estas palabras: "El 11 septiembre ba producido un cambio radical. Luego de los atentados terroristas, que nosotros condenamos, como condenamos todos los ataques contra civiles en cualquier parte del mundo, el gobierno de los Estados Unidos y sus aliados ban lanzado una operación militar masiva en nombre de la guerra contra el terrorismo... La guerra terrorista contra Afganistán tiende a extenderse sobre otros frentes. Es el comienzo de una guerra planetaria permanente para consolidar la dominación del gobierno norteamericano y sus aliados". Rigoberta Menchú, Premio Nobel de la Paz,

\section{6}


dijo: "Hoy dia las armas ban ganado, las bombas han ganado, la ausencia del diálogo ha ganado y, por esta razón, las organizaciones que podian garantizar una mediación han quedado debilitadas. Después de los atentados los temas sociales ban sido totalmente dejados a un lado, como si el dolor norteamericano bubiera opacado el dolor de todos los otros pueblos que sufren".

Para el gobierno de los Estados Unidos los problemas económi$\cos y$ sociales se relegan a un segundo plano ante la misión que la 'bistoria le ba dado de afianzar la seguridad duradera'. Sin embargo, el unilateralismo y utilitarismo con que el gobierno de los Estados Unidos pretende llevar a cabo la seguridad duradera comienza a generar distanciamientos de algunos aliados y bastantes no aliados. No todos están de acuerdo con el denominado "eje del mal", o paises "fuera de ley", y muchos gobiernos —incluida la OTANse sienten victimas de las 'alianzas flexibles' o aleatorias con que el equipo Bush quiere imponer sus principios y sus intereses.

Pareceria que los problemas de la globalización económica, social y humana han entrado en un proceso de hibernación y aislamiento frente a la poderosa publicidad imaginaria que sigue ampliando el ámbito del 'eje del mal', retrocediendo a la era de la guerra fría. Al mismo tiempo que G. W. Bush presenta el plan de recuperación de la economía de los Estados Unidos (Le Monde, 10-03-02), afirma que consagrará el resto de su mandato a la lucha contra el terrorismo mundial (El País, 11-03-02) El informe secreto del Pentágono, publicado en su integridad, o casi integridad, por The New York Times, amplía la anterior lista del eje del mal (Irak, Irán, Corea del Norte), integrando también a China y Rusia, por su potente arsenal nuclear, más otros posibles apéndices como Siria, Libia, o paises que reclamen la ayuda norteamericana contra el terrorismo, como Filipinas, Georgia, Yemen y tal vez el 'gobierno aliado' de Andrés Pastrana.

Robert McNamara, ex Secretario de Defensa de los Estados Unidos, 1961-1967, afirma que "La nueva politica nuclear de Bush es increible y peligrosa. Me temo que esto no sólo garantizará la ines- 
tabilidad estratégica, sino que también fomentará la proliferación. Es increible y peligroso... No puedo creerlo. Para empezar esto significa que EE.UU. no va a respetar sus 'Cláusulas de Garantía Negativa”, la garantía dada por todos los secretarios de Estado hasta el momento de que no utilizaremos armas nucleares contra potencias no nucleares, a no ser que se hayan asociado con una potencia nuclear para atacar a EE.UU. Todo esto socava el espiritu del Tratado de No Proliferación que fue prorrogado en el año 1995, por acuerdo formal. En vista de esta revisión, los Estados que buscan armas nucleares se sentirán abora justificados para hacerlo" (El País, 14-03-02).

Se profundiza asi la globalización del terror, al mismo tiempo que se debilitan algunas de las anteriores alianzas flexibles. Luego del 11 de septiembre, los gobiernos de Rusia y China se habian comprometido en la lucha antiterrorista, alianzas confirmadas en los mutuos encuentros de George W. Bush, Vladimir Putin y Zhan Ze Min en Washington, Moscú y Shanghai, respectivamente. Esta noticia llega en un momento en que Estados Unidos y Rusia avanzan un acuerdo, que tendrá lugar el próximo mes de mayo, sobre reducción de ojivas nucleares. Con qué ánimo tendrá lugar esta reunión, cuando el informe del Pentágono dice: "En el caso de que empeoren de forma significativa en el futuro las relaciones estadounidenses con Rusia, Estados Unidos puede necesitar revisar sus niveles de fuerza nuclear y su postura". Las alianzas flexibles se convierten en palabras huecas. China entra en el 'eje del mal' por la puerta de atrás, dadas sus exportaciones de armas a Irán, Siria y tecnología balistica a Pakistán, amén de su animosidad contra Taiwan.

Lo que parece estar en el primer punto de agenda es la intervención militar en Irak, si se niega a conceder 'poderes ilimitados' a los inspectores de la $O N U$, quienes deben verificar la posible existencia o preparación de armas bacteriológicas o similares. Condición que difícilmente puede aceptar el gobierno de Bagdad. El temor es que Estados Unidos tome estas decisiones "pasando por el 'ninguneo' de los aliados europeos y la asunción de que el uso 
militar de artefactos atómicos, expirada ya la disuasión global de la guerra fría, es de nuevo concebible en un futuro próximo". El primer ministro Tony Blair visitó e Bush a principios de abril, "con el fin de discutir el tipo de operación a emprender contra Irak". (El País, 11-03-02)

Si en los años 1999-2002 se ha bablado de la 'globalización mutilada' porque su esquema neoliberal gestaba un proceso de creciente exclusión de naciones y grupos sociales, la anunciada política antiterrorista de los Estados Unidos profundiza aún más el carácter unilateral de la globalización, sin caer en la cuenta de que también se hacen daño a si mismos en el corto y mediano plazo. El historiador Paul Kennedy, profesor de la Universidad de Yale, dice muy respetuosamente lo que se ha dicho en tantos testimonios personales $o$ en foros mundiales. "La simpatía que ha manifestado el extranjero luego del horror del 11 de septiembre ba sido sincera, pero dirigida a los inocentes y amados desaparecidos: a los que trabajaban en el World Trade Center, a los policias y bomberos. Habia también un sentimiento de compasión, nacido del temor de que algo parecido pudiera suceder en Sydney, Oslo o Nueva Delhi. Pero esto no significa un amor y un apoyo incondicional al Tio Sam".

Si bay norteamericanos que no se preocupan por las crecientes críticas en varios lugares del mundo y que piensan que el resto de paises debe aceptar incondicionalmente que Estados Unidos es el 'numero uno', hay otros conciudadanos, dice P. Kennedy, a quienes les preocupa que nos estemos aislando de los grandes desafíos de una sociedad mundializada. "Estos ciudadanos comprenden que Estados Unidos es responsable en gran parte de un mundo cada vez más interdependiente, por nuestras inversiones financieras, nuestras compras en el extranjero, nuestra revolución de las comunicaciones, nuestra cultura CNN y MTV, nuestro turismo e intercambio estudiantil, asi como por las presiones que ejercemos sobre las sociedades de otros paises para que acepten los acuerdos del comercio, de los flujos de capital, de la propiedad intelectual, de la legislación del trabajo y de las normas ambientales". Estos ciudadanos "temen que nos separemos excesivamente de un mundo al cual estamos

419

Lo globalización anda en pena 
ligados estrecha e inexorablemente. La impresión general que los Estados Unidos están dando es que no se preocupa por lo que piensa el resto del mundo... Cuando necesitamos ayuda — para capturar terroristas, congelar haberes financieros o encontrar bases aéreas para las tropas norteamericanas- entonces jugamos en equipo. Cuando los proyectos internacionales no nos interesan, retiramos nuestras canicas".

Es un gran servicio el que nos hace a nosotros, y sobre todo al gobierno norteamericano, el historiador Paul Kennedy al criticar "la política unilateralista de los Estados Unidos", simbolizada en el juego infantil de las bolitas, y que ha sido también cuestionada en los recientes foros mundiales de Davos, Nueva York y Porto Alegre. P. Kennedy termina bablando del liderazgo que boy debería emprender el pais 'numero uno': "Hablo de un liderazgo que se definiria por su amplitud de miras, por la aceptación de nuestra condición bumana común, por la convicción de tener tanto que aprender como enseñar a los demás. Un liderazgo que se dirija a los débiles y oprimidos del mundo entero y que mueva a los Estados Unidos a unirse a otras naciones privilegiadas capaces de ayudar juntos a aquellos que no pueden subsistir. Sobre todo, este liderazgo diría abiertamente al pueblo norteamericano y le explicaría, una y otra vez, por qué nuestro fundamental interés nacional es tomar en serio la suerte de nuestro planeta e invertir todo lo posible en su futuro. Si esto se realizara, lograríamos la promesa de Norteamérica y quedariamos sorprendidos al ver cuánto nos amarian de verdad". (Le Monde, 08-03-02)

Paul Kennedy hace una traducción libre del foro social de Porto Alegre. El gobierno norteamericano, ¿escuchará a 'los Paul Kennedy' que hablan desde dentro y desde fuera de los Estados Unidos? Seguramente no lo hará, porque abora sólo se escucha a si mismo y volverá a perder el campeonato de la defensa de la libertad, de la democracia y de los derechos bumanos. Aunque su economía comience a recuperarse, su globalización también 'anda en pena'. Nosotros seguiremos reflexionando el programa social de Porto Alegre con la esperanza de que algo podemos hacer por nosotros mismos.

\section{0}

Realidad 88, 2002 